\title{
SUBSTANTIATION OF DIAGNOSIS AND TREATMENT OF CHRONIC RECURRENT APHTHOUS STOMATITIS IN CROHN'S DISEASE
}

D0I: $10.36740 /$ WLek202003120

\author{
Oksana Y. Feleshtynska, Olena 0. Dyadyk \\ SHUPYK NATIONAL MEDICAL ACADEMY OF POSTGRADUATE EDUCATION, KYIV, UKRAINE
}

\begin{abstract}
The aim: To substantiate the diagnosis and treatment of chronic recurrent aphthous stomatitis in Crohn's disease.

Materials and methods: The analysis of diagnostic and treatment of 52 patients with chronic recurrent aphthous stomatitis in Crohn's disease (main group), mean age 31.8 + 2.3 was performed. The comparison group consisted of 50 patients with chronic recurrent aphthous stomatitis not associated with Crohn's disease (mean age $34.7+1.8$ ). Patients in both groups were studied for clinical manifestations, morphological and immunohistochemical studies the aphthae on the oral mucosa were performed. Results: An objective evaluation of the oral mucosa showed that the aphthae on the oral mucosa in patients of both groups did not differ visually. In the morphological study, the patients in the main group had granulomatous inflammation of the oral mucosa, characteristic of Crohn's disease, while the patients in the comparison group had fibrinous inflammation. Immunohistochemical study of the cell infiltrate phenotype in the area of the lesion revealed that the patients in the main group there prevailed CD68+macrophages, the appearance of both intraepithelial and cell infiltrates of T-lymphocyte suppressors, which is characteristic of Crohn's disease.

Conclusions: Diagnosis of chronic recurrent aphthous stomatitis in Crohn's disease is based on biopsy of the aphthae on the oral mucosa and their morphological examination, the results of which confirm the presence of granulomatous inflammation, with a large number of macrophages, the presence of T-lymphocytes, characteristic of Crohn's disease, while recurrent aphthous stomatitis of another genesis morphologically detect fibrinous inflammation.

The choice of therapeutic tactics for chronic recurrent aphthous stomatitis depends on the results of the morphological study. When granulomatous inflammation is detected in patients with chronic recurrent aphthous stomatitis, which is characteristic of Crohn's disease, in addition to topical treatment of the oral mucosa, specific therapy with mesalazine drugs is prescribed.
\end{abstract}

KEY WORDS: aphthous stomatitis, Crohn's disease, granulomatous inflammation

Wiad Lek. 2020;73(3):512-516

\section{INTRODUCTION}

Chronic recurrent aphthous stomatitis is an inflammation of the oral mucosa, manifested by the presence of aphthae, which is characterized by a prolonged course, frequent relapses without a certain pattern and often is accompanied by the gastrointestinal tract diseases [1,2]. Chronic recurrent aphthous stomatitis is observed in $11.5 \%$ of patients with Crohn's disease [3]. Diagnosis of chronic recurrent aphthous stomatitis in Crohn's disease in the absence of intestinal manifestations is often limited only by objective changes on the part of the oral mucosa [4].

Biopsy of the aphthae of the oral mucosa with morphological examination for the purpose of establishing a precise diagnosis is usually not performed [5]. The precise diagnosis of chronic recurrent aphthous stomatitis in Crohn's disease is established rather late, respectively, patients receive only local treatment, and specific treatment is not prescribed. The results of the treatment of chronic recurrent aphthous stomatitis in Crohn's disease should also be considered unsatisfactory, as the frequency of remissions and recurrences is quite high [6,7]. In our opinion, biopsy of the oral mucosa with morphological examination in chronic recurrent aphthous stomatitis will improve the diagnostic results and substantiate therapeutic tactics.

\section{THE AIM}

To substantiate the diagnosis and treatment of chronic recurrent aphthous stomatitis in Crohn's disease.

\section{MATERIALS AND METHODS}

The analysis of diagnostic and treatment of 52 patients with chronic recurrent aphthous stomatitis in Crohn's disease (main group) was performed. The age of patients was 18 to 65 (mean age $31.8 \pm 2.3$ ), among them the number of women was $29(55.8 \%)$ and men - 23 (44.2\%). The comparison group consisted of 50 patients with chronic recurrent aphthous stomatitis which was not associated with Crohn's disease. Age of patients from 18 to 65 years (mean age 34.7 $\pm 1.8)$, among them the number of women was $31(62 \%)$ and men $-19(38 \%)$.

Diagnosis of chronic recurrent aphthous stomatitis in patients in both groups included examination of complaints, history, objective examination of the oral mucosa and biopsy with morphological examination of the aphthae. The biopsy was performed on patients of both groups with their consent and according to the positive decision of the Bioethics Committee of Shupyk National Medical Academy of Postgraduate Education (Protocol No. 1 dated 03.01.2017). Under infiltration anesthesia, the aphthae on 
the oral mucosa with a conchotome were taken with tissue pieces $4-5 \mathrm{~mm}$ in size. The obtained biopsies were fixed in $10 \%$ solution of neutral buffered formalin $(\mathrm{pH} 7.4)$ for 24-36 hours, the material was prepared out according to the conventional method, it was poured into paraffin. From paraffin blocks on a rotary microtome NM 325 (Thermo Shandon, England) serial histological sections with a thickness of 4-5 $\mu \mathrm{m}$ were cut, which then were stained with $\mathrm{H} \& \mathrm{E}$, the PAS reaction $[8,9]$.

The immunohistochemical study was conducted to determine the phenotype of cellular infiltrate [10,11]. For immunohistochemical study, sections were placed on Super Frost Plus adhesive glasses (Menzel, Germany). Citrate buffer (pH6), EDTA buffer, $\mathrm{pH} 8$ were used for high-temperature treatment of antigen epitopes. We used antibodies and an UltraVision Quanto HRP detection system, a Quanto DAB chromogen, manufactured by Thermo Fisher Scientific (the USA). Monoclonal murine antibodies to CD68/macrophage marker (KP1 clone), monoclonal rabbit antibodies to CD8+/ marker T-lymphocyte suppressors (3B5). Pathomorphological examination and photoarchiving were performed using ZEISS (Germany) optical microscopes with «Axio Imager. A2» data processing system with $5 \mathrm{x}, 10 \mathrm{x}, 20 \mathrm{x}, 40 \mathrm{x}, 1.5$ binoculars and 10 eyeglasses with ERc 5s camera, «Carl Zeiss» Primo Star with Axiocam 105 color camera.

All patients underwent topical treatment using anti-inflammatory, antiseptic, analgesic, keratoplastic drugs. After obtaining the results of morphological examination the aphthae on the oral mucosa, the treatment was reviewed and supplemented as necessary.

\section{RESULTS}

Patients in the main group and the comparison group had such major complaints as one or more aphthae of the oral mucosa, pain during meals and conversation. In 7 (13.5\%) patients of the main group, besides manifestations from the oral cavity, there were complaints from the intestine, namely abdominal pain and recurrent diarrhea.

The results of an objective study in patients in both groups were comparable. The aphthae had an oval or circular shape, with a diameter of $6 \pm 3.2 \mathrm{~mm}$, surrounded by an inflammatory rim of red color, covered with fibrinous plaque, around the aphtha - infiltration of the mucous membrane. Palpation is very painful, mild.

The results of morphological study of biopsies in patients of the main group showed the presence of expressed degenerative changes in mucous membranes in the areas of the lesions, mainly in the form of vacuolar and/or balloon dystrophy in the epithelium, areas of parakeratosis, focal manifestations of inflammatory reaction in the form of intraepithelial leukocytes, cells with signs of apoptosis, focal acanthosis. In the submucosal layer, there was a pronounced, mainly limited by the type of granulomatous inflammation, lymphohistiocytic cell infiltrate, which spread on separate areas to the epithelial layer. Signs of dysmucoidosis were observed in the stroma of the site of focal sclerosis in the vessels of the microcirculatory blood- stream, in some part - sclerosis (Figure 1).

To determine the phenotype of cellular infiltrate in the lesion sites the immunohistochemical study was conducted. In areas of cellular infiltration in the form of granulomatous inflammation, a marked positive expression of a large number of CD68+macrophages was observed (Figure 2).

In addition, we found that among the cells of inflammation there were present T-lymphocyte suppressors, which were localized, both intraepithelially and subepithelially in the area of cellular infiltrate in the stroma (Figure 3). Such a morphological pattern corresponds to Crohn's disease. The diagnosis of Crohn's disease in the patients of the main group was also confirmed by a gastroenterologist and the results of ileocolonoscopy, biopsy of the mucous membrane of the distal ileum with morphological examination.

In the pathomorphological study of biopsies in patients of the comparison group we found mainly fibrinous and fibrinous-necrotic type of inflammation of the mucous membrane - in the form of ulcers and films of fibrin on the surface, which was accompanied by a sharp decrease in mucus secretion in these areas. Cell inflammatory infiltrate at the bottom and at the edges of the ulcers is mainly represented by neutrophilic leukocytes, monocytes, focal lymphocytes. In the epithelium, along with the alterative-exudative changes there is observed edematous layer of the epithelium, focal spongiosis, which can lead to the formation of microvavities. Areas of ulcer - the defect of the epithelium is gradually filled by fibrinous exudate, which is strongly bound to the adjacent soft tissues (Figure 4).

In the areas near the defects there is preserved multilayered flat epithelium with degenerative changes, subepithelially irregular mostly moderately expressed lympho-histio-plasmacytic cell infiltration, including around the vessels of the microcirculatory bloodstream (Figure 5).

During immunohistochemical study in the ulceration area macrophage expression was not observed, outside the sites of alterative-exudative changes macrophages were found subepithelially in the stroma in the cell infiltrate with less pronounced positive expression and in a smaller number than in the main group (Figure 6).

T-lymphocyte suppressors were found outside the areas of ulceration, both intraepithelially and in areas of cellular infiltration, but their number and expression level were smaller than in the main group (Figure 7).

The results of the pathomorphological study served as the basis for the differential approach in the choice of therapeutic tactics in patients of the two groups. Patients in the comparison group who were found to have morphologically fibrinous inflammation, with areas of ulcer characteristic of chronic recurrent aphthous stomatitis, were prescribed topical treatment, which included irrigation of the oral mucosa with anti-inflammatory, antiseptic, analgesic drugs, anti-inflammatory and keratin applications. Patients in the main group who had granulomatous inflammation, characteristic of chronic recurrent aphthous stomatitis in Crohn's disease, were prescribed specific therapy with mesalazine for 1 month, in addition to topical treatment of aphthae on the oral mucosa. 


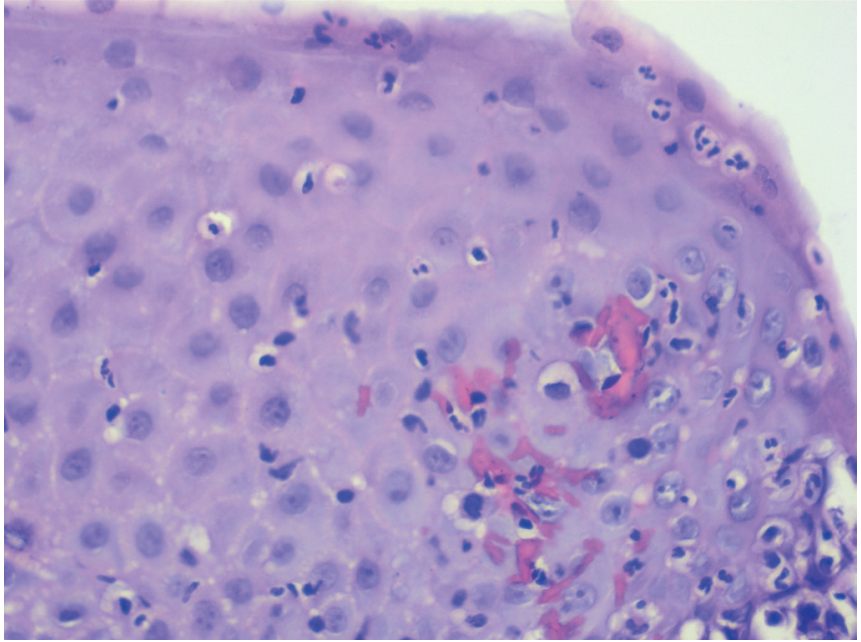

Figure 1. Expressed degenerative changes in the mucous membrane, areas of parakeratosis, accumulation of intraepithelial leukocytes, cells with signs of apoptosis. Hematoxylin and eosin staining, x400.

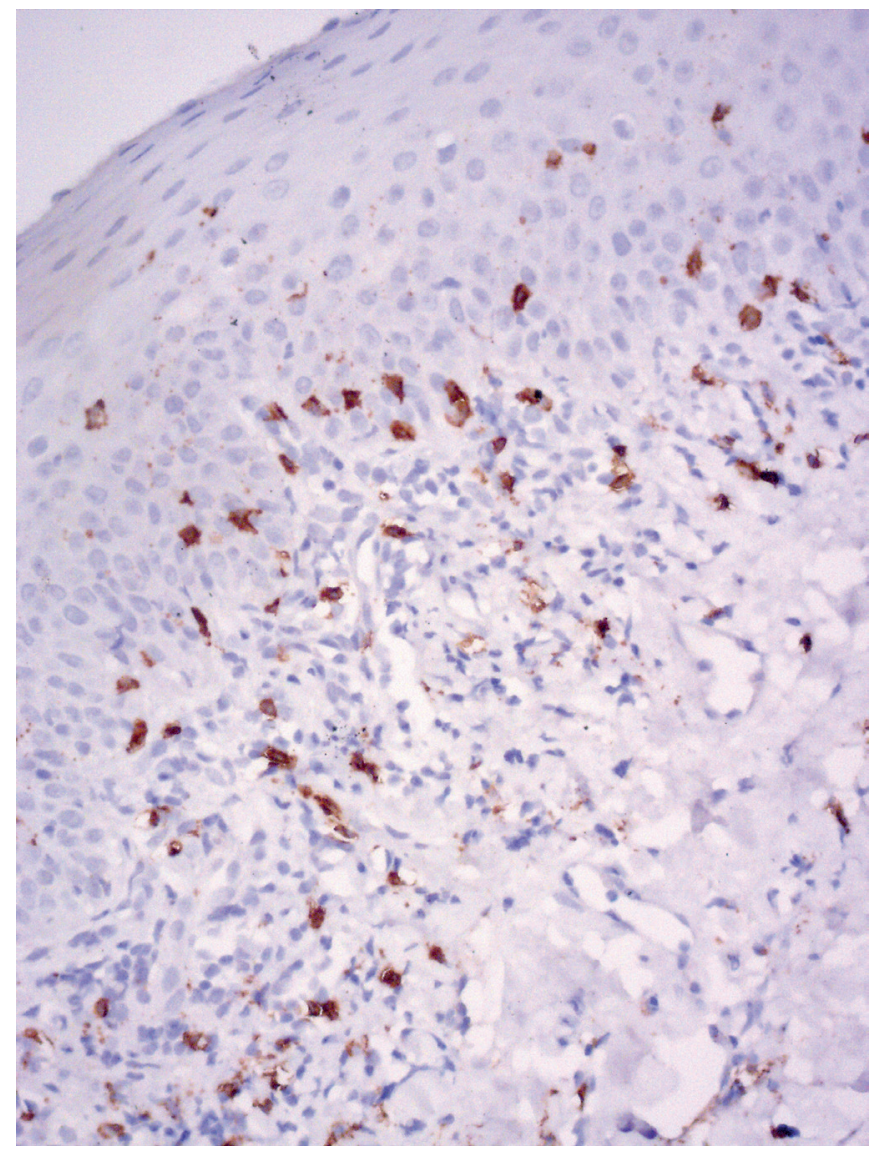

Figure 3. Pronounced positive expression of T-lymphocyte suppressors intraperitoneally, in the area of cellular infiltrate. Immunohistochemical study with monoclonal antibodies to CD8+, x200.

\section{DISCUSSION}

The results of a study of clinical manifestations of chronic recurrent aphthous stomatitis in the main and comparison groups of patients indicate that they are similar and differ only in $13.5 \%$ of patients in the main group, who

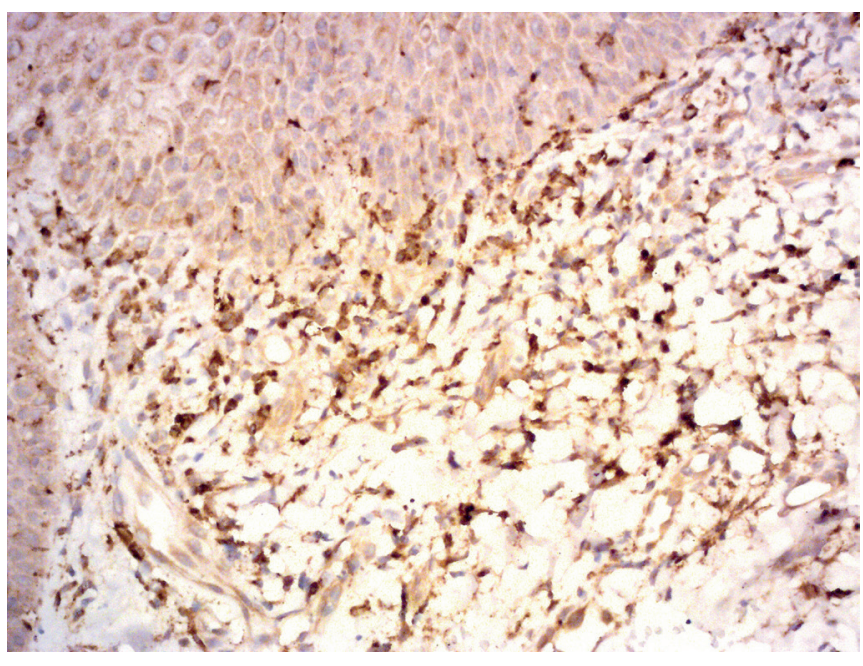

Figure 2. Area of cell infiltrate by granulomatous inflammation type, large number of macrophages with pronounced expression. Immunohistochemical study with monoclonal antibodies to CD68, x200.

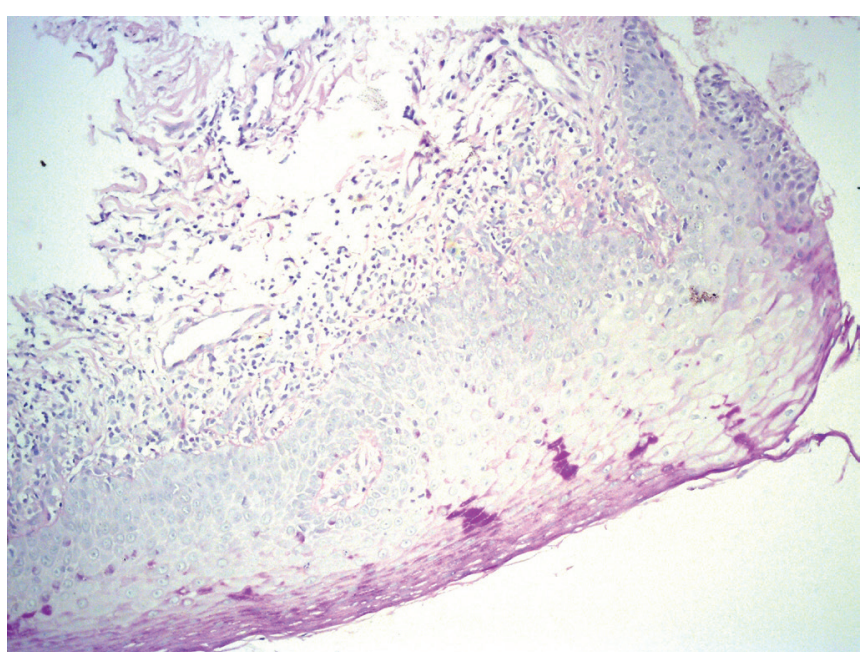

Figure 4. Ulcers, fibrin on the surface, a sharp decrease in mucus production, focal spongiosis, leukocyte cell infiltrate. PAS, x100.

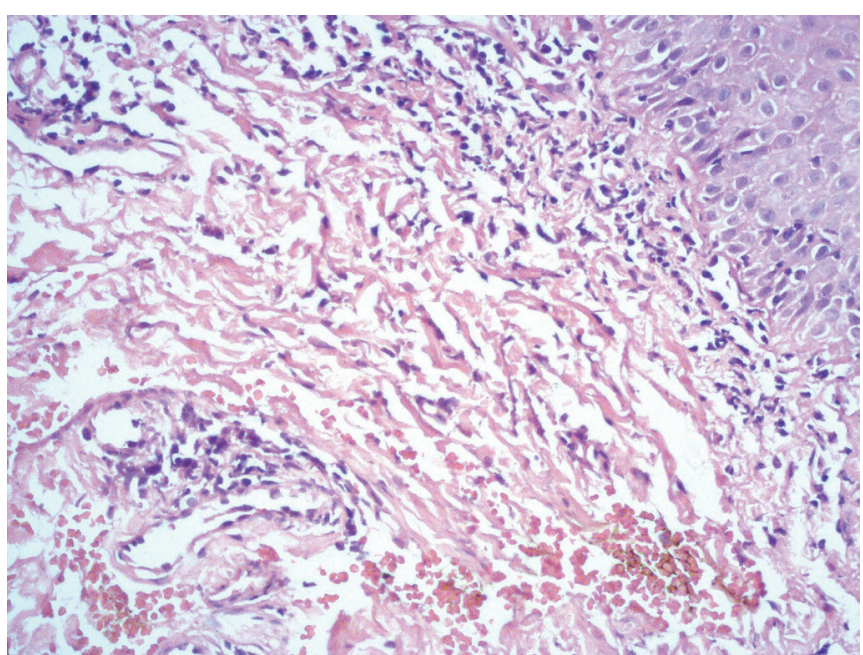

Figure 5. Lympho-histio-plasmacytic, perivascular cell infiltration is moderately expressed in the stroma. Hematoxylin and eosin staining, x200. 


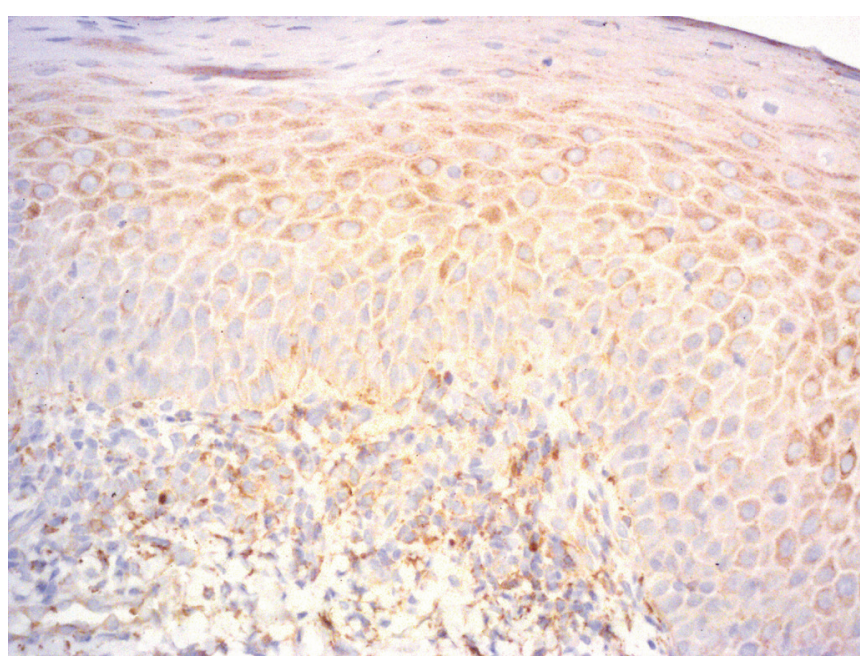

Figure 6. Poorly pronounced expression of macrophages, mainly subepithelially in the stroma. Immunohistochemical study with monoclonal antibodies to CD68+, x200.

had a combination of clinical symptoms of oral cavity with intestinal disorders. Objective evaluation of the oral mucosa showed that aphthae on the oral mucosa in patients in the main group and comparison group were not visually different. Such a clinical picture does not allow us to determine the nature of inflammation and accordingly to appoint adequate treatment. The results of morphological examination of the aphthae showed the difference in inflammation of the oral mucosa in the patients of the main group and the comparison group. Granulomatous inflammation of the oral mucosa characteristic of Crohn's disease was found in patients in the main group, whereas fibrinous inflammation was found in the comparison group. Immunohistochemical study of the cell infiltrate phenotype in the area of the lesion revealed that in the patients of the main group there prevailed macrophages, the appearance of both intraepithelial and cell infiltrates of T-lymphocyte suppressors, which is characteristic of Crohn's disease. This made it possible to review the treatment, namely the patients of the main group, to prescribe, in addition to topical treatment, mesalazine group drugs for 1 month, which lead to a stable remission of $12 \pm 1.2$ months. This was possible only due to a morphological study of the oral mucosa, which helped establish the nature of inflammation.

\section{CONCLUSIONS}

Diagnosis of chronic recurrent aphthous stomatitis in Crohn's disease is based on biopsy of the mucous membranes of the oral cavity and their morphological studies, the results of which confirm the presence of granulomatous inflammation, with a large number of macrophages, the presence of T-lymphocyte suppressors, characteristic of Crohn's disease, while fibrinous inflammation is morphologically detected in chronic recurrent aphthous stomatitis of other genesis.

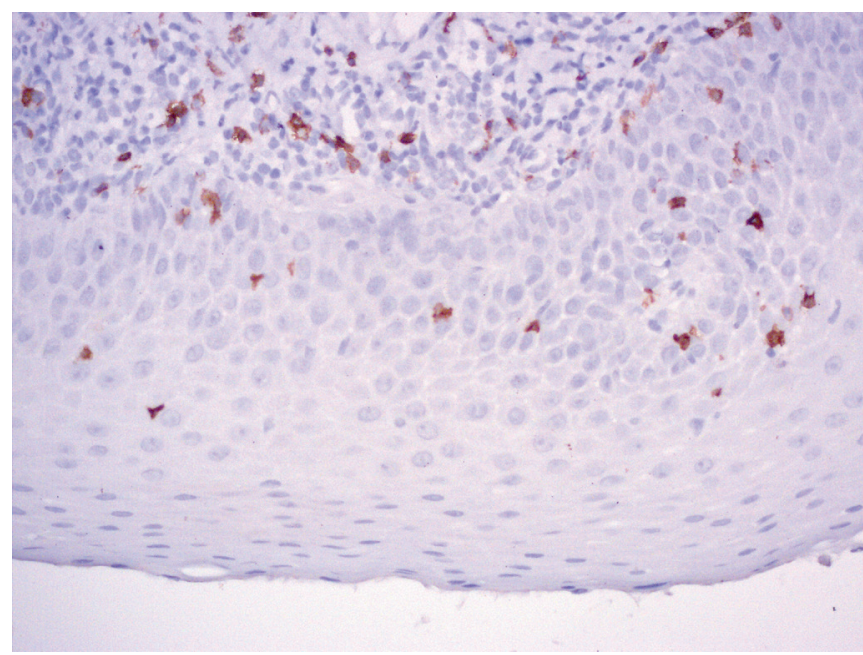

Figure 7. Moderately pronounced positive expression of T-lymphocyte suppressors intraepithelially, in the stroma subepithelially in the cell infiltrate. Immunohistochemical study with monoclonal antibodies to CD8 +, x200.

The choice of therapeutic tactics in chronic recurrent aphthous stomatitis depends on the results of the morphological study. When granulomatous inflammation is detected in patients with chronic recurrent aphthous stomatitis, which is characteristic of Crohn's disease, in addition to topical treatment of the oral mucosa, specific therapy with mesalazine drugs is prescribed.

\section{REFERENCES}

1. Danylevskyi M. F., Borysenko A. V., Antonenko M. U. et al. Zahvoriuvannia slyzovoi obolonky porojnyny rota [Disease of the mucous membrane of the oral cavity]. Kyiv: Medycyna; 2010,640 p. (in Ukrainian).

2. Edgar NR, Saleh D, Miller RA. Recurrent aphthous stomatitis: A review. J Clin Aesthet Dermatol. 2017; 10(3): 26-36.

3. Volosovets T. N., Dyadyk 0. 0., Feleshtynska 0. Ya. Manifestni proiavy hronichnogo recydyvuiuchogo aftoznogo stomatytu pry hvorobi Krona [Manifestation of chronic recurrent aphthous stomatitis in Crohn's disease]. The world of medicine and biology. 2018; 3(65): 42-45 (in Ukrainian).

4. Karman B. Lankarani, Gholam Reza Sivandzadeh, Shima Hassanpour. Oral manifestation in inflammatory bowel disease: A review. 2013; 19(46): 8571 - 8579.

5. Belenguer-Guallar I, Jimenez-Soriano Y, Claramunt-Lozano A. Treatment of recurrent aphthous stomatitis. A literature review. J Clin Exp Dent. 2014; 6(2): 168-174.

6. Savychuk 0. V., Zaiceva le. M., Nemyrovych lu. P. et al. Likuvannia hronichnogo recydyvuiuchogo aftoznogo stomatytu [Treatment of chronic recurrent aphthous stomatitis]. Modern dentistry. 2015; 2: 37-39 (in Ukrainian).

7. Vavricka SR, Schoepfer A, Scharl M et al. Extraintestinal Manifestations of Inflammatory Bowel Disease. Inflamm Bowel Dis. 2015;21: 1982-1992.

8. Markovsky V. D., Tumansky V. 0., Sorokina I. V. et al. Patomorfologiia [Pathomorphology]. Kyiv: Medycyna; 2015, p. 40-52, p. 621-655. (in Ukrainian).

9. Rosai J. Surgical Pathology. In: Rosai and Ackerman's. Surgical Pathology Seven edition/edited by Rosai J. Elsevier Inc.; 2011, Vol-1, Ch. 2,3, p.25-95. 
10. Dabbs D. Diagnostic Immunohistochemistry, 4th Edition Theranostic and genomic applications; 2014, 960p.

11. Petrov S. V., Raihlin N. T. Rukovodstvo po immunogistohimicheskoi diagnostike opyholei cheloveka [Guidelines for the immunohistochemical diagnosis of human tumors]. Kazan; 2012: 612p. (in Russian).

The work is a fragment of the research work of the Institute of Dentistry of Shupyk National Medical Academy of Postgraduate Education "Clinical and laboratory substantiation of the use of modern medical technologies in the complex treatment and rehabilitation of major dental diseases", state registration number $0117 \mathrm{U} 006451$.

ORCID and contributionship:

Oksana Y. Feleshtynska - ID 0000-0001-7692-1824 ${ }^{A, C, D}$

Olena O. Dyadyk - ID 0000-0002-9912-4286 ${ }^{\text {B,E,F }}$

\section{Conflict of interest:}

The Authors declare no conflict of interest.

\section{CORRESPONDING AUTHOR}

Oksana Y. Feleshtynska

Ukraine, Kyiv, Pryozerna str., 4, app. 89,

Tel.: +380672812561

e-mail:feleshtynska@gmail.com

Received: 17.01 .2020

Accepted: 05.03 .2020

A - Work concept and design, B - Data collection and analysis, C - Responsibility for statistical analysis,

D-Writing the article, $\mathbf{E}$-Critical review, $\mathbf{F}$ - Final approval of the article 